Annales Missiologici Posnanienses t. 23 (2018), s. 147-163

doi: 10.14746/amp.2018.23.10

PIOTR NAWROT

Uniwersytet im. Adama Mickiewicza w Poznaniu

Wydział Teologiczny

\title{
Música para rezos y liturgias de la Semana Santa de los archivos misionales en Bolivia
}

\section{Objetivo}

El presente ensayo expone la revisión de algunos textos escritos por los misioneros y superiores de la Compañía de Jesús donde se narra sobre las celebraciones de la Semana Santa en las antiguas reducciones de los jesuitas y la música que se utilizaba en dicha festividad. Iniciamos en Domingo de la Pasión, y se prosigue hasta el Sábado Santo, indagando si - con base en la colecciones de música de las misiones de Chiquitos y de Moxos - es posible reconstruir la sonoridad de estas fiestas según lo que notifica el texto. El artículo incluye la transcripción de algunas de las obras musicales citadas en los textos de los jesuitas. Si en la conclusión de este estudio se demostrara que tal reconstrucción global de la música de la Semana Santa es posible, el proyecto podría ser profundizado en otro estudio como una natural continuación de este resultado.

\section{Introducción}

En el calendario litúrgico la Semana Santa es el tiempo más intenso de celebraciones litúrgicas y piadosas de todo el año. Desde el Domingo de Ramos hasta el Sábado Santo la iglesia se convierte en un lugar de incesante oración, sobre todo en la hora del Triduo Pascual. En el contexto de la Iglesia Hispanoamericana, particularmente en las comunidades donde se fundaron las antiguas reducciones, el Viernes Santo tiene una connotación especial; es, por muchos, considerado como el momento más sacro y solemne de todo el año, tiempo en el que cualquier otra actividad que no sea utilizada para el rezo, po- 
dría ser considerada sacrilegio. Los encuentros de oración durante esta semana incluyen múltiples cantos, varios de los cuales se ejecuta una sola vez al año, y su realización requiere de una larga preparación entre los músicos profesionales, así como del pueblo que participa de estos encuentros.

Las misiones entre los indios de América Meridional fueron conocidas por sus exuberantes liturgias, que - de acuerdo a los misioneros, superiores, obispos y viajeros que las conocieron - igualaban, o hasta superaban, las solemnes liturgias de las principales catedrales de Europa. Por ser iglesias y comunidades locales, sus rezos siempre fueron enraizados en las culturas originarias de América. Es por ello que buscaremos presentar algunos momentos que nos ayuden a captar la influencia de los indígenas sobre las liturgias de la Semana Santa.

Ya que hasta el más breve repaso por el repertorio musical para la Semana Santa (guardado en los archivos misionales de Bolivia) es inmenso y su estudio global bastaría para más de una tesis doctoral, aquí solamente señalaremos sus momentos constitutivos.

\section{Informes sobre la Semana Santa en las reducciones jesuíticas}

El tema de Dios encarnado, muerto en la Cruz, fue un tema central de la prédica de los misioneros desde el primer encuentro entre los jesuitas y los indios. Cuando se llegaba al acuerdo de que los religiosos fueran permitidos para comenzar sus actividades evangélicas - ya sea por el avance de la religión cristiana como por el crecimiento de una nueva sociedad -, la alianza entre las partes siempre fue firmada en la elevación de la cruz situada en la aldea del encuentro.

El misionero fundador no iba solo, sino acompañado por indígenas de las reducciones fundadas en la zona anteriormente. Y estos indígenas podían pertenecer a tribus hermanas o enemistadas, e incluso en guerra con la tribu a la que llegaban. Luego, en un corto tiempo, desde la "firma del contrato", comenzaba la construcción del templo, donde se desarrollarían actividades de culto, prédica, enseñanza del catecismo; en síntesis, todo lo referente a la fe y, al mismo tiempo, a la constitución de una escuela, donde se enseñarían letras y oficios para formar gobierno y habilitar a la comunidad a ejercer todos los oficios necesarios para levantar y hacer funcionar una misión, que nunca contaba con más de dos o tres misioneros. El rol de estos últimos fue más el de supervisar el adelanto que se daba en cada misión y no ejercer todos los trabajos. Estos últimos siempre fueron ejecutados por los indios artesanos, bajo la guía de sus propios capataces y en conformidad con las disposiciones enviadas por el gobierno del pueblo, formado por los líderes indios y los misioneros. Y este 
adelanto fue milagrosamente vertiginoso, tanto en el aspecto espiritual como material; «milagrosamente», ya que en pocos años - aproximadamente en una década - la misión parecía alcanzar rasgos de una colectividad bien formada.

Lo ejemplifica muy bien el informe de Diego de Eguíluz - superior, profesor y escritor jesuita nacido en Perú-, que en 1696 envió al superior general, Tirso González.

Eguíluz nunca estuvo en Moxos. Su narración se construyó a partir de las cartas de los misioneros de Moxos que regularmente tuvieron que enviar a sus superiores los informes para instruirlos a detalle sobre las nuevas exploraciones en la zona, fundación de cada uno de los pueblos, descripción de las iglesias, bautizos, vida sacramental, avance de la doctrina cristiana, aprendizaje de las lenguas y la organización misma de la vida en las reducciones. Su informe relata el estado de cada una de las misiones que en 1696 existían en el territorio de Moxos: Loreto, Trinidad, San Ignacio, San Francisco Javier, San José, San Francisco de Borja. Con respecto a esta última misión, Eguíluz nos confirmó cuán acelerados pudieron haber sido el crecimiento y la madurez de las misiones y cuán solemnes fueron las celebraciones de la Semana Santa en las reducciones en América desde su fundación. Él dice:

\section{Sexta reducción de San Francisco de Borja de Churimanas}

... Fundóse por el mes de Diciembre del año de 1693... por los Padres Francisco de Borja e Ignacio de Sotomayor...

Y para hacer concepto del estado en que se halla esta nueva Cristiandad en lo espiritual, baste decir el modo y estilo que han tenido desde el primer año de bautizados en celebrar la Semana Santa por el cual se conocerá lo que florecen en todo lo demás de piedad y devoción. Después de confesados todos los del Pueblo, aún los muy niños, porque los traen sus padres para que se vayan enseñando, y comulgados los más, a que se da principio desde el Primer Domingo de Cuaresma, se disponen los monumentos muy decentes y procesión, el Jueves Santo para el entierro de Señor y el Viernes Santo, después del Sermón de Pasión, en que se dan muchas bofetadas y golpes de pechos, se hace la adoración de la Santa Cruz, que todos adoran con mucha compostura y devoción, llevando los padres y las madres a sus hijos pequeños a adorar al Señor, cuidado muy singular que tienen para criarlos y acostumbrarlos a cosas de devoción. Luego se ordena la procesión por la plaza y calles principales, llevando en unas andas la imagen de bulto de Cristo Crucificado y en otras la de la Santísima Virgen, también de bulto, con más de doscientas luces, en un silencio y compostura tan grande que no se oye una palabra, si no es los 
azotes de un crecido número de penitentes de sangre, arrastrando sogas y palo pesados y otros vestidos de Nazarenos, aspados con cruces a los hombros y las voces de los coros que van cantando el Miserere. Y leen en dichas tristes en su lengua la Pasión de Nuestro Señor Jesucristo. Acabada la procesión persevera la iglesia llena de gente, porque se van alternando varios coros San Calisque cantan lamentaciones tristes, mientras duran los penitentes que van pasando delante del Monumento, haciendo reverencia y mas recia disciplina a vista de la imagen de Cristo Crucificado. Preguntándole en una ocasión de estas un Padre a un mocetón por que se había azotado más fuerte que los otros sus compañeros, respondió: porque los otros no pensaban como yo en sus pecados. Yo meditaba la Pasión de Nuestro Señor y en los infiernos que merecía por mis culpas y así arreciaba la mano. El Sábado Santo al entonar la Gloria entran varios géneros de danzas a la Iglesia. Con que es día de mucha alegría y regocijo para todo el Pueblo que acude a la Misa cantada, y la misma solemnidad hay el Domino de Pascua. ${ }^{1}$

Uno de los más ilustres cronistas entre los misioneros jesuitas que vivieron en América fue José Cardiel. Treinta años trabajó entre los indios guaraníes y después de la expulsión de los misioneros de los pueblos, ya desde Europa (Faenza, Italia), redactó varios documentos con increíble cantidad de detalles sobre la vida en las reducciones. A pesar del paso de los años y de la distancia geográfica, Cardiel se acordaba de cada detalle de la vida en las reducciones. En relación a la Semana Santa, que describe con mucho pormenor, particularmente conmovedoras eran las representaciones del Viernes Santo. Se las hacía después del sermón sobre la Pasión y sus partes cantadas empleaban textos en lenguas autóctonas. Según el relato de Cardiel:

La Semana Santa se celebra con todas las solemnidades de una Catedral, con continua asistencia de toda la música a los Maitines, Misas y Procesiones... [El Viernes Santo] predícase la Pasión, y después de ella van saliendo varios pasos, de la Columna, de la Corona con espinas, etc.... Mas antes de los Pasos, hay otra función de mucha ternura y compasión; y es que van saliendo hasta 10 ó 12 niños uno tras otro, vestidos con sotana, cada uno con una insignia de la Pasión puesta en alto, y cantando con voz muy lastimera en un tono que moverá a compasión a la mayor dureza. Uno dice un verso en su lengua: Veis aqui los cordeles con que los

\footnotetext{
${ }^{1}$ Diego de Eguíluz, Relacion de la Mision Apostolica de los Moxos en esta Provincia del Peru de la Compania de Jesus que remite su Provincial Padre Diego de Eguiluz a Nuestro Muy Reverendo Padre Tirso Gonzalez, General. Ano 1696. Archivum Romanum Societatis Iesu, Perú 21, Peruana Litteræ Annuæ, Tomus III, 1633-1700. Status Missionis Indorum, quos Moxos Vocant. Peruanæ, 1696. [ff. 62v y 63r.] Copia. Original en el Archivo Nacional de Lima, Leg. 1155.
} 
crueles sayones ataron las manos de nuestro piadosísimo Salvador, después de haber hecho con ellos tantos beneficios a ellos y a nosotros. Este es el retorno que nuestros pecados dan a tantos favores. ;Ay! ;Ay! ;Ay, ingratitud sin igual! Otro prosigue: Veis aquí la corona con que, etc., y acaba: ;Ay! ;Ay!, etc., exagerando nuestras ingratitudes y mostrando grande compasión. Y así prosiguen cantando la significación de cada insignia. Y la música, después de cantado el Miserere en el discurso de la procesión, va repitiendo en el mismo canto de los niños los mismos versos y significaciones a tres y cuatro voces con sus bajones. ${ }^{2}$

También en Moxos, la música de la Pasión empleaba textos en lenguas autóctonas. El ceremonial del Viernes Santo para la liturgia de la adoración de la Santa Cruz y procesión por la plaza al son del salmo Miserere fue esencialmente el mismo para todas las misiones. En la celebración nocturna del Sábado de Gloria se insertaban, asimismo, danzas litúrgicas.

... El Viernes Santo, después del Sermón de Pasión... se hace la adoración de la Santa Cruz, que todos adoran con mucha compostura y devoción... Luego se ordena la procesión por la plaza y calles principales, llevando en unas andas la imagen de bulto de Cristo Crucificado y en otras la de la Santísima Virgen, también de bulto, con más de doscientas luces, en un silencio y compostura tan grande que no se oye una palabra, si no es los azotes... y las voces de los coros que van cantando el Miserere. Y leen en dichas tristes en su lengua la Pasión de Nuestro Señor Jesucristo. Acabada la procesión persevera la iglesia llena de gente, porque se van alternando varios coros que cantan lamentaciones tristes... El Sábado Santo al entonar la Gloria entran varios géneros de danzas a la iglesia. Con que es día de mucha alegría y regocijo para todo el Pueblo, que acude a la Misa cantada, y la misma solemnidad hay el Domingo de Pascua. ${ }^{3}$

Es provechoso también para nuestro fin citar un documento más, redactado por el misionero de Moxos, Estanislaus Arlet, uno de los más ilustres jesuitas de su tiempo, fundador de San Pedro de Moxos, misionero en Loreto, catedrático de la teología moral en la Universidad San Francisco Xavier de Chuquisaca, prefecto de estudios superiores y admonitor en el Colegio de La Plata, hombre ilustre y santo. Nacido en Opole, Polonia, llegó a Lima, Perú, en 1996, y murió en Potosí en 1717. En su carta al P. General sobre las reducciones jesuitas entre los indios Canisianos dice:

\footnotetext{
2 José Cardiel, Carta y relacion de las misiones de la Provincia del Paraguay, 1747. Archivo de la Provincia de Toledo, Madrid, n. 151.

${ }^{3}$ Diego de Eguíluz, Relacion de la Mision Apostolica de los Moxos en esta Provincia del Peru de la Compania de Jesus que remite su Provincial Padre Diego de Eguiluz a Nuestro Muy Reverendo Padre Tyrso Gonzalez, General. Ano 1696. Archivum Romanum Societatis Iesu, Perú 21, Peruana Litteræ Annuæ, Tomus III, 1633-1700, ff. 62v-63r.
} 
En la Semana Santa se celebran las tinieblas con toda la música. Los instrumentos que se tocan en este tiempo son solamente violones, bajones, flautas de coro, espinetas, o clavicordios, y en algunos pueblos se toca también liras, instrumento muy dulce y devoto. Cuando se canta el Miserere toman su disciplina los Indios en reverencia de la Pasión del Señor. El Jueves Santo a la noche hay sermón de Pasión, el cual concluido sale la procesión que es tan devota, que no se puede explicar sin lagrimas. En esta forma: se visten como 30 niños de edad de 9 a 10 años con vestidos muy decentes y talares: a cada uno se le da un paso de la Pasión, que va en medio de dos muchachos con linternas en las manos: paso y linternas se llevan en alto para que se vea todo con claridad. Todos estos niños están dispuestos en orden en el patio de los padres, cerrada la puerta de la Iglesia, que mira a aquella parte. Sale el Padre con su pluvial, y toma asiento al lado de dicha puerta, y luego abierta esta, sale un niño con la soga con que prendieron a Cristo, y se pone en medio de la Iglesia, para cuyo fin se deja libre una espaciosa calle, que va hasta la puerta principal hacia donde se han de encaminar todos. Al entrar, pues, dicho niño canta en un tono muy tierno al son de Bajones, y chirimías roncas una copilla en su lengua, que expresa el instrumento con que fue por míos pecados ligado el Redentor, la cual concluida hace al Santísimo profunda genuflexión, y en medio de sus dos linternas se encamina hacia el pórtico de la Iglesia. Entra otro con una manopla, otro con una corona, otro con la cruz \&. Y cada uno canta como el primero expresando el instrumento, que lleva en la mano, y lo que [fin f. 23v] con el padeció el Señor. La función es larga, y muy devota. En el resto de la procesión van sin cantar dichos niños, y mientras dura esta, que es al rededor de la plaza, como la de Corpus, los Músicos van cantando el Miserere. Cuando se acaba este, cantan las coplas, que cantaron los niños en la Iglesia. Llevan en andas varios pasos de la Pasión, que son estatuas de culto. Y cuando sale de la Iglesia Cristo a la columna, y su Madre Dolorosa, prorrumpen en llanto, y gritos las mujeres, manifestando el sentimiento que ocupa sus corazones. Después no se oyen sino caxas roncas, y clarines roncos, y un confuso ruido de azotes. Azótanse casi todos los que no llevan andas o gobiernan la procesión, en la qual no se hoye una palabra. Sus azotes son en forma de una penca sembrada de puntas de fierro, que les hierre las espaldas, con mucho derramamiento de sangre. ${ }^{4}[\mathrm{f} .24 \mathrm{a}]$

Sería posible multiplicar textos sobre la Semana Santa en las misiones, ya que varios de los misioneros, superiores y obispos que conocieron los pueblos jesuíticos han dejado testimonios sobre el tema. No obstante, para nuestro fin, tal extensión no es necesaria. Los textos citados ya bastan para confirmar que entre Domingo de Ramos y Domingo de Resurrección las misiones se convertían en un momento de constante rezo y canto. Pasaremos a confrontar los in-

\footnotetext{
${ }^{4}$ Archivo de Alcalá. Caja 84. Perú = (II)1. 2. Carta del P. Estanislao Arlet al P. General sobre la misión o Reducción de los indios "Canisianos" del Perú. (1-IX-1698), f. 24 a. [Hay otra copia de esta carta impresa, en latin, Lg. 3,6].
} 
formes con documentación musical guardada en los archivos musicales de las misiones jesuíticas de Bolivia y con las prácticas de rezos que todavía están, en gran parte, vivos en los pueblos del país.

Ahora reconstruyamos los momentos que componen encuentros litúrgicos y devocionales del Viernes Santo.

\section{Vía crucis, ayer y hoy}

El vía crucis en América Hispana, tanto colonial como misional, se hacía en general - y esto perduró hasta el presente - no dentro de una catedral o iglesia misional, sino por las calles. Cada viernes de la Santa Cuaresma los fieles se congregaban a cierta distancia de la iglesia y llevando una cruz caminaban hacia la iglesia, parando en las casas donde los patrones de la vivienda preparaban un altar, decorado de santos y, a menudo, de los instrumentos de la pasión (ramos y plantas verdes), sobre los cuales - en algunos lugares de las selva beniana que conocí - colgaban frutas, que uno podía recoger al concluir la visita. Fuera de la Santa Cruz, en la procesión, podían llevarse también el retrato o la estatua de la Virgen Dolorosa.

En varios pueblos de las reducciones jesuíticas, la entrada a la misión fue marcada por el vía crucis. La primera estación comenzaba a considerable distancia de las casas de los indios - unos dos o tres kilómetros de trayecto y conducía hacia el templo que siempre fue el edificio central de la plaza principal del pueblo misional. Las catorce cruces del camino no eran altas, sino que medían aproximadamente un metro y cuarenta centímetros de altura. Eran simples, sin mucho tallado, sin texto, tan solo con números correspondientes a cada estación.

Esto permite suponer que el pueblo conoce las catorce estaciones de memoria. Y efectivamente es así. Los mayores, con facilidad, sitúan el misterio de cada estación, aunque -principalmente por el respeto que tienen a las autoridades tradicionales - tal procesión no la preside cualquier participante del rezo, sino alguien con un alto cargo en la jerarquía de oficios religiosos, que puede ser, por ejemplo, un catequista, un sacristán o un músico. Si el vía crucis se hace por esta trayectoria, ya no se construyen altares, aunque el entorno inmediato de cada cruz se limpia de herbaje y para el pase de la procesión se ponen hierbas más decoradas. Aunque en cada templo había también vía crucis, nunca logré participar de esta popular práctica religiosa en América, dentro del edificio. 


\section{El salmo Miserere}

En cada una de las colecciones de música misional, tanto de Chiquitos como de Moxos, hay cuatro arreglos polifónicos de este salmo de carácter penitencial. Dos de estos arreglos son los mismos para ambas misiones, aunque Chiquitos pertenecía a la Provincia Jesuítica del Paraguay, mientras que Moxos a la Provincia del Perú. Quizás las dos composiciones pertenecían a lo que se llamaba el repertorio musical común para todas las reducciones jesuíticas. Según Arlet, durante la procesión alrededor de la plaza, fueron los músicos de oficio, y no el pueblo caminante, quienes entonaban el salmo. La documentación lo confirma, ya que perduraron composiciones para coro a cuatro voces e instrumentos, así como otras para dos coros e instrumentos. Ello nos sugiere que los coros tuvieron que ser grandes, compuestos de varios cantantes. Cuando estas procesiones se hacían muy extensas los músicos estaban preparados a ejecutar más de un arreglo del mismo texto, sin correr el riesgo de que la procesión se quedara sin música. Es menester añadir que en los pueblos de las misiones, en semejantes procesiones, los hombres llevaban los bultos conmemorativos de diferentes momentos de la Pasión de Cristo (flagelación, Cristo con la Cruz, etc.), mientras que las mujeres iban aparte, siguiendo al primer grupo, con la Virgen Dolorosa. La gente piadosa camina en silencio y se escucha canto ejecutado por las capillas musicales del lugar.

No obstante, en otros momentos, el texto parece sugerir que no fue el coro, sino el penitente mismo que cantaba el Miserere. La colección de Chiquitos ha salvado dos documentos musicales, del grupo llamado monodia litúrgica, que podrían ser utilizados para este fin. Uno de ellos, A 13, en el encabezamiento hasta indica: Miserere mo Santa Missa au Jueves Santo. El otro, R 04, parece intercalar partes polifónicas (versos impares) con monódicas (versos pares); en el encabezamiento dice: Mo unama Congregantes (para la congregación). De este arreglo se ha salvado tan solo la parte del bajo.

Lo que no se ha encontrado en la documentación musical de las misiones jesuíticas o de otras familias religiosas que trabajaron entre los indios, son copias del salmo Miserere traducido a lenguas locales.

\section{Misa cantada}

No hay pruebas de que en las misiones se celebrasen misas recitadas. Cada misa tenía que tener al menos un pequeño coro, pero su tamaño y el número de instrumentos que lo acompañaban podrían variar, de acuerdo al estado del avance de crecimiento de la misión y al grado de solemnidad. En cada misa también tenían que servir los monaguillos, cuyo número variaban de dos 
a seis, o más muchachos bien entrenados en su oficio. Los misioneros que salían al nuevo territorio en busca de las comunidades indígenas llevaban consigo un número de músicos para asistir con sus cantos la misa que se oficiaban en plena selva, al aire libre. Básicamente, la liturgia para la Semana Santa fue de carácter grave y sobrio, acompañada tan solo por cantos a cappella. Aunque en las misiones se ejercía el canto llano durante la liturgia, el canto a una sola voz, sin acompañamiento de instrumentos, fue una peculiaridad poco aplicada. Por lo general, la misa fue acompañada por un coro polifónico, a tres o cuatro voces, con al menos un instrumento de continuo, un violón o un bajón. El uso de ostros instrumentos fue restringido.

Las colecciones misionales confirman ese suceso de cosas. En Moxos, Misa Araujo de Cuaresma, a cuatro voces (SSAT) y continuo, así como Misa Feria (Signatura 740), caben en este esquema: voces e instrumentos de continuo. También, Misa para las Ferias de Semana Santa en Chiquitos, sigue el mismo formato. Pero Misa Feria (Signatura 741), en Moxos - que es una composición de Giovanni Battista Bassani y que por algún músico de Moxos fue también adaptada para la fiesta de Navidad, mientras que en Chiquitos la misma misa fue destinada para el festival de San José - es una composición para el coro a 4, dos violines y un continuo. La admisión de dos violines en una misa cantada durante la Cuaresma podría significar que las normativas sobre el uso de música en las misiones fuera flexible.

\section{Bendición del fuego}

Arlet habla también de la bendición del fuego, que se hacía el Sábado Santo. No se refiere tan solo a la oración pronunciada por el sacerdote sobre la fogata, de la cual se encenderá el cirio pascual, sino de la devoción de los indios que llevan parte de este fuego a sus casas para encender su leña. Dice Arlet:

[...] Se hace nuevo fuego el Sábado Santo, según el ritual y los Indios llevan por devoción de este fuego a sus casas para encender su leña. ${ }^{5}$

En la selva de Bolivia esta costumbre sigue en pie y es celosamente observada por las comunidades. Cinco años consecutivos, entre 2008 al 2013, tuve la oportunidad de participar en las celebraciones de la Semana Santa en una comunidad indígena de la selva del Beni, Bolivia, San José del río Cabito. Los

\footnotetext{
${ }^{5}$ Archivo de Alcalá. Caja 84. Perú = (II)1. 2. Carta del P. Estanislao Arlet al P. General sobre la misión o Reducción de los indios "Canisianos" del Perú. (1-IX-1698), f. 24 b. [Hay otra copia de esta carta impresa, en latin, Lg. 3, 6]
} 
pobladores de esta comunidad son directos descendientes de los indígenas que en el siglo XVIII fueron evangelizados por los misioneros jesuitas. La mayoría de las oraciones a las que se refieren Cardiel, Arlet y Eguíluz siguen en pie. Incluso todavía se guarda la antigua costumbre de que el Jueves Santo, después de haber cenado, el corregidor del pueblo, junto a sus ayudantes, van casa por casa y aseguran que todas las fogatas estén apagadas.

El Viernes Santo no se prepara comida caliente. Generalmente este día es un día del estricto ayuno, pues no se come nada durante todo el día. Se le llama fuego nuevo y se bendice el Sábado Santo por la mañana. Temprano, cerca de las 6 a. m., en frente de la capilla, se reúnen los representantes de las casas de los indios, cada uno trayendo consigo una leña, y una por una se apilan juntas, en forma de un cono. Cuando ya no falta nadie, se prende el fuego, lo que produce, entre los reunidos, visible emoción. Una vez la fogata está bien ardiente, en cortas palabras se explica el significado de la ceremonia y luego se bendice el fuego. Al concluir la oración, cada uno busca su leña prendida, la lleva a su casa y con esta enciende su fuego para la cocina, con la que preparan la comida del día. Los habitantes de San José del río Cabito aseguran que nadie come si no se bendice primero este fuego nuevo que, luego, esparce su calor para la leña común que se utiliza en la cocina. No he conocido ningún canto que estuviera ligado a esta ceremonia.

\section{Lenguas nativas}

Por las disposiciones de los Concilios de Lima, el anuncio del cristianismo a los indígenas tenía que hacerse en lenguas locales y no en español. Cada misionero hablaba al menos una o más lenguas del lugar. Así, la prédica del catecismo, los sermones, las oraciones comunes, la comunicación diaria, todo ello, se hacía en lingua franca. Tan solo la misa, vísperas y la liturgia formal se hacían en latín. En las misiones de Chiquitos han sobrevivido colecciones de sermones destinadas para las fiestas del año litúrgico que se mantienen en uso hasta la fecha. Estas colecciones se las dice una vez al año, a cargo de una autoridad del pueblo, frente a la entrada de la iglesia, con las puertas abiertas y mirando el altar mayor. No las lee el sacerdote, ni tampoco se las pronuncia desde el púlpito.

El repertorio musical con textos en lenguas nativas comprende: óperas, cantadas, letanías, himnos, pasiones, lamentaciones, vía crucis y cantos piadosos. Hay también ejemplos de mezcla entre el texto en latín y lengua del lugar, así como entre español - mucho menos frecuente que el primer caso - y lengua local. La colección de manuscritos de las misiones de Moxos es 
particularmente voluminosa en este rubro y encierra más de 100 cantos de esta naturaleza, de los cuales cerca de 50 son para la Semana Santa.

Un canto de Moxos, llamado lamentación, no necesariamente es la traducción de las Lamentaciones de Jeremías a lenguas locales. Más a menudo, el texto misional sigue la estructura y los temas abordados por el profeta del Antiguo Testamento, pero lo hace de forma libre, mezclando sus propias emociones, rezos y precepciones sobre la pasión de Cristo con el narrativo bíblico. Algo parecido ocurre en relación a las pasiones en lenguas locales. El repertorio de Moxos no es una simple traducción de los cuatro evangelios que relatan sobre la pasión de Cristo, sino la libre adaptación local donde aparecen más figuras que en el relato del Nuevo Testamento. Justamente este repertorio - lamentaciones, pasiones y canto devocional en lenguas nativas - es donde más fácil se percibe la influencia indígena sobre el repertorio musical de las misiones.

Una de las características más notorias de este repertorio es que mayormente se realiza a una sola voz, acompañada de un instrumento de continuo. La estructura formal es binaria, en cuya parte A (estrofas) canta solista, mientras que en la parte B (refrán) canta toda la comunidad. Además, el texto de las coplas se renueva con cada repetición y el texto del refrán es fijo. Menos veces se encontró que una lamentación o pasión fuera concebida para dos o más voces con acompañamiento de violines, aunque tal arreglo también existe.

En comparación con Moxos, el repertorio de Chiquitos en este rubro es más reducido, pero existente. Ya que las liturgias de las reducciones de los jesuitas fueron similares en todas las provincias, se supone que tal repertorio tuvo que existir, pero con el paso del tiempo se extravió o fue reemplazado por nuevas composiciones. Es también posible que los simples cantos, estróficos y sin instrumentación, fueran anotados en otro tipo de cuaderno que utilizaban - como una especie de cancionero - los cantantes amateur - no miembros de la capilla musical de la misión-. Tal práctica es todavía conocida en varias comunidades de Moxos.

\section{Las lamentaciones de Jeremías}

A partir de la colección de Chiquitos se puede confirmar que en las misiones se cantaba todo el matutinum del Jueves Santo, con salmos y sus correspondientes antífonas, con las lamentaciones del profeta Jeremías y con los nueve responsorios. Mientras que los salmos se cantaban a una sola voz, pero en dos coros, las lamentaciones se cantaban a dos o más voces; y los nueve responsorios, en coro a cuatro voces. Estos últimos son de Domenico Zipoli, 
misionero jesuita que dejó el puesto de maestro de capilla en la Chiesa del Sacro Nome di Gesù (Roma) para componer, desde Córdoba (Argentina), para los músicos indios. Considerando el gran talento del músico jesuita y la habilidad de los músicos locales en interpretar estas hojas musicales, no sorprende que varios testigos de aquellas liturgias en la selva de América las comparasen con las mejores catedrales de Europa, o hasta con los coros angelicales del cielo.

\section{Las pasiones en latín}

Antiguamente, durante la Semana Santa se leían los cuatro relatos evangélicos de la Pasión de Cristo, en la siguiente norma: Domingo de la Pasión, según San Mateo; Martes Santo, según San Marcos; Miércoles Santo, según San Lucas; y Viernes Santo, según San Juan. En las reducciones entre los indios se respetaba esta práctica.

En la colección de Chiquitos existe la introducción polifónica a la Pasión según San Mateo y a la Pasión según San Juan. En ambos casos, la copia de la que se dispone es incompleta, faltando algunas de las voces y totalmente carente de instrumentos. Es de suponer que después del anuncio del autor del texto de la Pasión, que se hacía en coro a 4, el cantante pasaba a ejecutar la melodía gregoriana, de la que disponían en todas las misiones.

\section{Secuencia: Stabat mater dolorosa}

En la mayoría de las iglesias misionales Stabat mater se refiere no tan solo al texto de la popular secuencia que data del siglo XIII y se mantuvo en uso hasta el presente, sino también a un altar o a un bulto de la Virgen Dolorosa, el cual el Viernes Santo se llevaba en procesión alrededor de la plaza principal. Durante esta procesión se podía cantar algo en honor a la Virgen, pero esto era un canto simple, a una voz, acompañada de violines y de algún instrumento de continuo: arpa, órgano portátil o procesional u otro todavía. El Stabat mater procesional en la colecciones misionales no se nutría de los versos del fray Jacopone da Todi, sino de su libre adaptación.

El Stabat mater dolorosa solemne se cantaba el Viernes Santo por la noche en la iglesia, con coro, sin orquesta, con tan solo algún instrumento de continuo. La colección de Moxos dispone de cuatro arreglos de este texto, entre procesional y solemne, mientras que el repertorio de Chiquitos los tiene tres. Tan solo uno de los tres es completo. Pero, aparentemente, los tres son de carácter solemne. 


\section{Yyaî Jesuchristo}


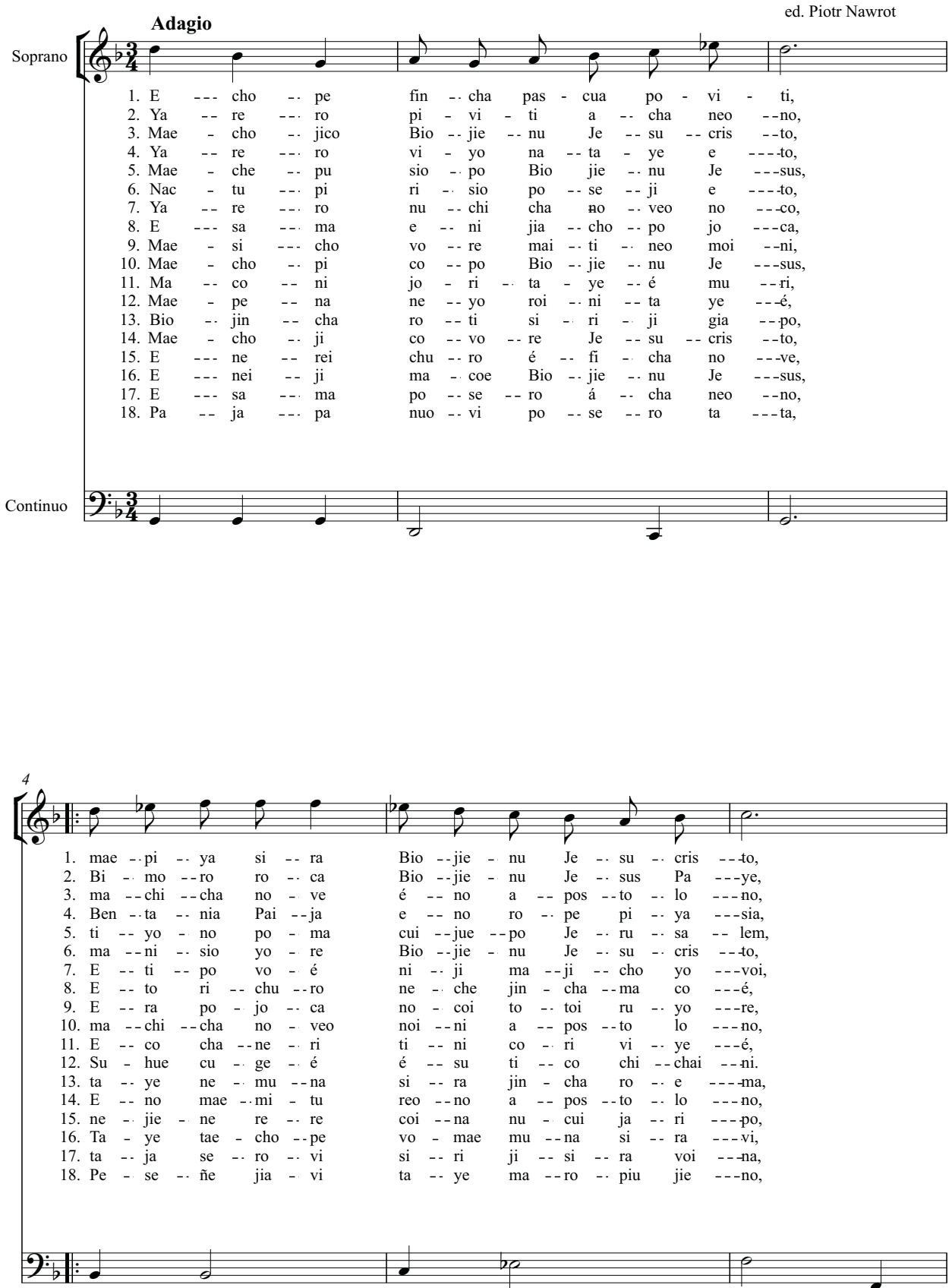


\section{Letanías de Pasión}

También dos letanías que hay en la colección de Moxos, Letanía Sangre de Pasión y la Letanía de la Nuestra Señora de Dolores podrían ser utilizadas en procesiones y rezos comunitarios de la Semana Santa. Estas dos letanías no son más que la misma composición, para el coro a cuatro voces (SSAT) y continuo, con dos textos distintos. Ninguna copia deja alguna pista aclaratoria sobre a cuál de las celebraciones pertenecían estas dos obras.

\section{Improperios}

Varias crónicas de los misioneros relatan sobre la extensa, postmeridiana liturgia del Viernes Santo en la que se hacía la adoración de la Santa Cruz. En múltiples pueblos de la selva de Bolivia este ritual sigue en pie. Todos los reunidos en la iglesia se acercan a la Santa Cruz colocada en el centro del templo, a los pies del altar, para besar la santa imagen. La mayoría la besa tres veces: la frente herida por las espinas, el costado perforado por la lanza del costado y los pies atravesados por los clavos. El ambiente que se produce es solemne y muy emotivo, ya que varios se conmueven a lágrimas mientras besan la santa imagen. Luego, donan una ofrenda - que en los pueblos más pobres podrían ser dos huevos, un poco de arroz, plátano o semejante $-\mathrm{y}$ vuelven a su lugar. Mientras tanto, la capilla musical entona varios cantos llamados improperios.

Ambas colecciones misionales disponen de obras musicales para tal liturgia. Entre Chiquitos y Moxos hay tres arreglos corales del Popule meus. No obstante, en Moxos hay también dos arreglos del mismo, con el texto traducido al castellano, Santo Dios. Santo fuerte.

\section{Conclusión}

Este estudio confirma que las narraciones sobre la celebración de la Semana Santa en las reducciones jesuíticas dejadas por los misioneros Cardiel, Arlet y otros, así como por superiores como Eguiluz, son auténticas y corresponden a la verdad, sin exageración o disminución alguna. Desde el Domingo de Ramos hasta el Sábado Santo, las misiones eran lugares de constante oración cantada, con diversas melodías, comenzando por las cuatro narraciones de la Pasión de Cristo, lamentaciones del profeta Jeremías, misa en latín, improperios, secuencias, vía crucis, letanías, cantos con texto en lenguas nativas y todavía de otras composiciones para la Semana Santa. La mayoría de los cantos referidos en los informes citados fueron ubicados en las colecciones musicales 
provenientes de las misiones de Chiquitos y de Moxos. Incluso, a pesar del paso de más de trescientos años desde el tiempo en que las cartas fueron redactadas, varias liturgias siguen vivas en las comunidades cristianas de la selva de Bolivia. Es por ello que, después de la confrontación entre narraciones, contenido de las colecciones musicales de las misiones y la tradición viva, opinamos que es posible reconstruir casi todo el repertorio de la música sacra para la Semana Santa, tal cual se la celebraba en las primeras décadas del siglo XVIII.

\section{A B S T R A C T}

The present essay exposes the revision of some texts written by the missionaries and superiors of the Society of Jesus where it is narrated about the celebrations of Holy Week in the former Jesuit reductions among the South-American Indians. It speaks about music that was used in formal and popular liturgies of the Holy Week. We begin on Passion Sunday and continue until Holy Saturday, asking if - based on the music collections of the missions of Chiquitos and Moxos - it is possible to reconstruct the sound of these festivities according to what the texts written from the $18^{\text {th }}$ century missions testify. The article includes the transcription of some of the musical works cited in the texts of the Jesuits. If in the conclusion of this study it is demonstrated that such a global reconstruction of the music of Holy Week is possible, the project could be deepened in another study as a natural continuation of this result.

Keywords: Indians; Jesuits; music; reconstruction of sound; Holy Week; mission history

Palabras clave: Indios; Jesuitas; música; reconstrucción del sonido; Semana Santa; historia de la misión

\section{BIBLIOGRAPHY}

Archivo de Alcalá. Caja 84. Perú = (II)1. 2. Carta del P. Estanislao Arlet al P. General sobre la misión o Reducción de los indios "Canisianos" del Perú. (1-IX-1698), f. 24 a. [Hay otra copia de esta carta impresa, en latin, Lg. 3, 6].

Cardiel, José. Carta y relación de las misiones de la Provincia del Paraguay, 1747. Archivo de la Provincia de Toledo, Madrid, n. 151.

Eguíluz de, Diego. Relación de la Misión Apostólica de los Moxos en esta Provincia del Perú de la Compañía de Jesús que remite su Provincial Padre Diego de Eguiluz a Nuestro Muy Reverendo Padre Tyrso González, General. Año 1696. Archivum Romanum Societatis Iesu, Perú 21, Peruana Litteræ Annuæ, Tomus III, 1633-1700, ff. 62v-63r.

Eguíluz de, Diego. Relación de la Misión Apostólica de los Moxos en esta Provincia del Perú de la Compañia de Jesús que remite su Provincial Padre Diego de Eguiluz a Nuestro Muy Reverendo Padre Tirso González, General. Año 1696. Archivum Romanum Societatis Iesu, Perú 21, Pe- 
ruana Litteræ Annuæ, Tomus III, 1633-1700. Status Missionis Indorum, quos Moxos Vocant. Peruanæ, 1696. [ff. 62v y 63r.] Copia. Original en el Archivo Nacional de Lima, Leg. 1155.

Fr. Prof. Dr. hab. Piotr Navrot SVD Profesor del Departamento de Teología Pastoral y Derecho Canónico de la Facultad de Teología de la Universidad de Adam Mickiewicz en Poznań, investigador en el Departamento de Musicología en el Ministerio de Cultura en Bolivia, Director de los Archivos de la Misión de los indios Moxo en San Igancio de Moxos (Bolivia) y los indios Guarayo en Urubicha (Bolivia). 